\title{
The Spectrum of Motivations, Expectations and Attitudes in Technical Development Cooperation
}

\section{White, Pamela}

2015-01

White , P 2015 , ' The Spectrum of Motivations, Expectations and Attitudes in Technical

Development Cooperation ' , Forum for Development Studies , vol. 42 , no. 1 , pp. 89-112 . https://doi.org/10.1080/08

http://hdl.handle.net/10138/256767

https://doi.org/10.1080/08039410.2014.997790

Downloaded from Helda, University of Helsinki institutional repository.

This is an electronic reprint of the original article.

This reprint may differ from the original in pagination and typographic detail.

Please cite the original version. 
This is an Accepted Manuscript of an article published by Taylor \& Francis in Forum for Development Studies, Volume 42, Issue 1, January 2015, pp 89-112. DOI:

10.1080/08039410.2014.997790

\title{
THE SPECTRUM OF MOTIVATIONS, EXPERIENCES AND ATTITUDES IN TECHNICAL DEVELOPMENT COOPERATION
}

\section{Pamela White}

\begin{abstract}
This article examines the motivations and experiences of persons working in different technical cooperation roles within international development cooperation, analysing how they differ, yet contain a common thread. The study consists of interviews and a questionnaire directed to volunteers, NGO staff, Junior Professional Officers, technical advisors, researchers and donor staff - as well as personal reflections. I consider the literature on motivations and gift theory, including binary positions applied to development work, such as work/career-volunteer; selfish-altruistic motivations. An element of altruism was common for many, but was more frequently vocalized by the older respondents, while career imperatives appeared to be more important for the younger cohort. I found considerable fluidity of movement of individuals between the categories of technical cooperation, and no matter their starting point, a tendency to stay in development throughout their career and identify with a development culture or habitus.
\end{abstract}

\section{Key words}

technical cooperation; development culture; altruism; motivation; development cooperation

\section{INTRODUCTION}

Why do well-educated westerners choose to live and work in a developing country? Are they driven by salary, an interest in an exotic job and lifestyle, guilt or a desire to learn and 'do good'? The spectrum of technical development cooperation (including volunteers, NGO staff, donor staff well-paid consultants) includes varying qualification and experience pre-requisites, and a range of motivations, expectations and rewards.

Much of the recent ethnography of aid ('aidnography') looks at discrete roles in the spectrum. Mosse (2005) speaks from his experience as a bilateral consultant and Eyben (2008) from her 
work as bilateral donor staff. Vaux (2001), Eriksson Baaz (2005) and de Jong (2011) study NGO staff. Watts (2002), Devereux (2010) and Smith and Laurie (2011) focus on volunteers. Stirrat (2008) is a significant work for this study, as he introduces the stereotypes of 'mercenary, missionary and misfit', and notes that while some persons working in development cooperation might stay within one category, others move between them.

This paper takes the discussion further by looking at a cohort of Finnish development workers, who have worked in various roles. I find that there is considerable crossover in categories and discuss the chronological progression of individuals' working careers. I examine the motivations and experiences of volunteers, JPOs, NGO staff, researchers, donor staff and technical advisors/consultants (all of whom have been on long-term assignments in developing countries). I analyse their differences and whether their attitudes towards development cooperation have changed as they gain experience and work in different roles. The paper is based on analysis of interviews and written questionnaires. While the respondents were Finnish development workers, the findings are globally applicable. I consider the literature on motivations and gift theory, and compare to the self-identified positions of my respondents. I also reflect on my own experience of moving from solidarity worker, to long-term volunteer and NGO staffer, and eventually working for a consulting company - balancing altruism with professional demands of career development.

\section{DEFINING TECHNICAL COOPERATION}

For the purposes of this paper I consider a broad definition of international development workers, encompassing a spectrum of roles of westerners working in developing countries (I do not look at the increasing numbers of development workers from developing countries).

Some are well paid and some fund themselves. Employers range from universities, NGOs, recipient country organisations, bilateral and multilaterally-funded donor projects and agencies and embassies. The Organisation for Economic Cooperation and Development / Development Assistance Committee (OECD/DAC) definition of technical cooperation (also known as technical assistance) is "the provision of know-how in the form of personnel ....this comprises activities financed by a donor country whose primary purpose is to augment the level of knowledge, skills, technical know-how or productive aptitudes of the population of developing countries'. The definition also includes volunteers 'under wholly or partly publicly financed or publicly controlled volunteer programmes, receiving a stipend in compensation for their services', as well as development researchers funded by the donor (OECD/DAC, 2010). A more traditional definition 
of technical assistance refers to long or short term consultants or 'experts', that are indeed one of the categories of my study; however in this study I consider technical cooperation broadly, also including self-funded volunteers; and junior professional officers (JPOs) in bilateral projects and multilateral organisations, supported by Finland since the 1960s.

The spectrum (or continuum) of persons working in development could be described in the graphic below, with varying qualification and experience prerequisites, and a variation in power, expectations and rewards. This is a complicated world to portray with a diagram. Figure 1 clusters the roles in three groups, although there is considerable overlapping (this is reinforced by Figure 3, which shows that all the respondents had held at least three roles at the time of interview). Bilateral donor project-linked consultants are located on the cluster with bilateral donors; and multilateral donor staff on another cluster; with church-based workers, volunteers and NGOs on a 'third sector' grouping of categories. I located researchers as 'floating' close to the third sector cluster, based on the self-identification of researchers I interviewed. Yet in practice, many also worked as consultants at times for the donors (and were funded by them in their research). To some extent it sets the flexible roles on the left against the more rigid demands (constructed by donors and terms of reference) for measurable work outcomes on the right. Power and salaries tend to be greater for the roles on the right hand side, yet at the same time they are more constrained to defined activities. Expectations of measureable 'outputs' from volunteers and NGO staff are generally lower, along with their perceived power, and they have more opportunity to develop relationships with their peers on a similar level (although this is also changing, with the increased financier focus on demonstrating impacts). The graphic doesn't imply that roles are fixed, nor does it include all links. Many people have worked in more than one category, typically moving from left to right, though sometimes circulating between categories, and some have even held multiple roles at the same time. It is an attempt to encompass my interpretation of the possible categories of technical cooperation (based on my experience). I have used the diagram in interviews, asking respondents to identify their current and earlier positions on the spectrum. Traditionally it has been assumed that altruism is the main motivation for those on the left-hand side, whereas more selfish motivations of career, salary and professional development are considered to motivate those to the right. This study explores this assumption - is there a clear difference in motivation, according to the role held?

At the professional consultant end of the spectrum, salaries may be high (particularly in comparison to local staff) and workers have considerable power. However, this doesn't apply to 
all western development workers (eg. volunteers), nor are money and power the only drivers. All make sacrifices in their personal lives and face discomfort and risk.

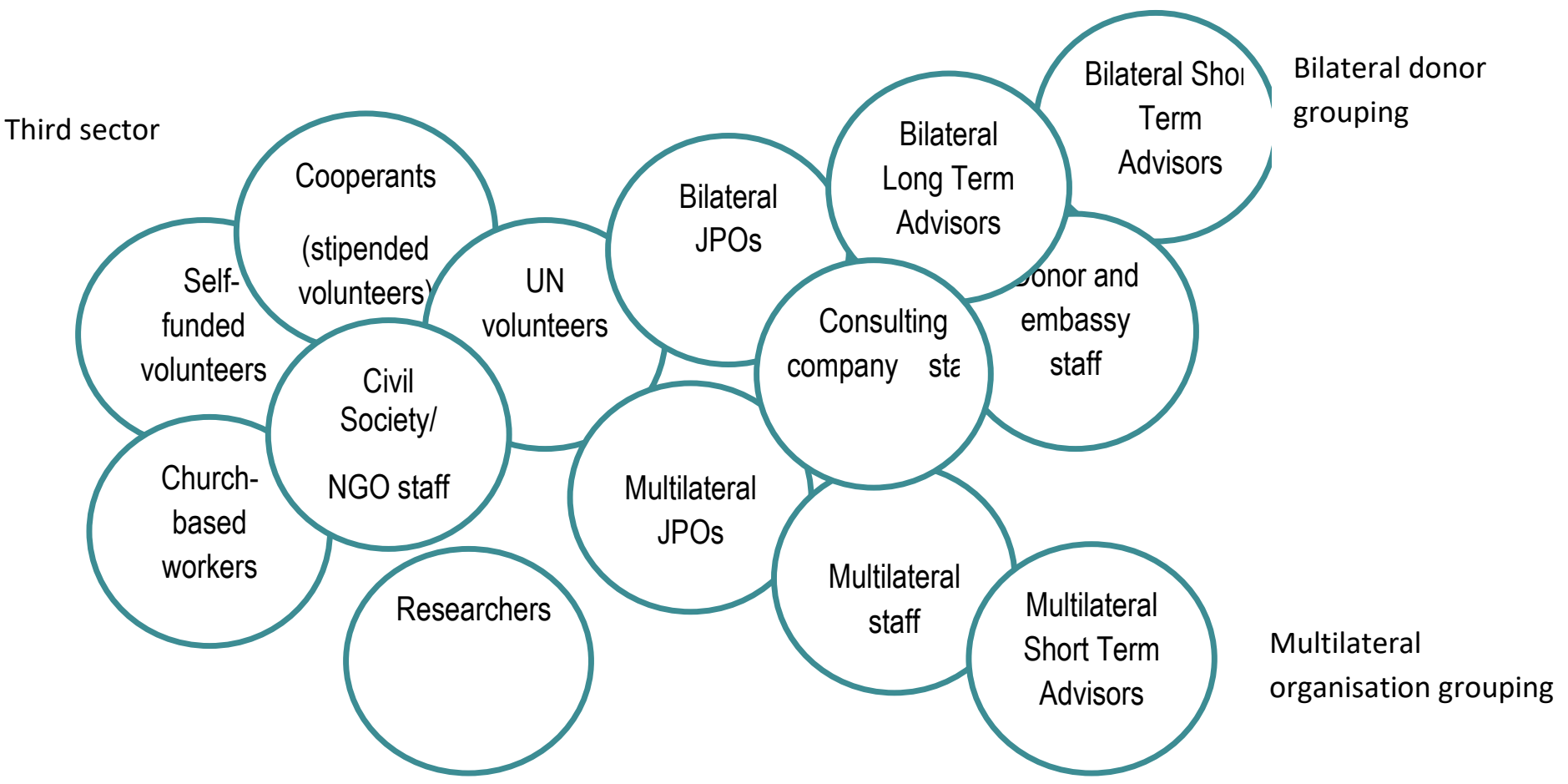

Figure 1: Spectrum of technical development cooperation

\section{CONCEPTUAL UNDERSTANDING}

\section{Setting the scene in Finnish development cooperation}

Development cooperation has changed considerably over the last sixty years. Post-colonial development cooperation originated in most countries as technical transfer managed by donor governments (Brett 2003). Post WWII, Finns were sent to work with the UN as technical experts. At the same time Finland began to send technical advisers to developing countries, and to carry out training programs - either employed directly by the Finnish Government, or via institutional or consulting company partners (Koponen, 2005). The first Committee for Development Aid was established in 1961 (Koponen, 1999). Finland began sending Junior Professional Officers (JPOs) to the UN organisations in 1965 (and this continues today) (White et al, 2011).

In the 1980s and '90s there was a focus on large development projects and technical know-how transfer. Neo-liberal market theory dominated policy and institutional reform programmes in the 1980s. (Brett 2003). Forss et al (1988) evaluated the effectiveness of Nordic development cooperation and sketched the changing face of aid. As with most development cooperation of the 
time, in the 1980s, the majority of Nordic technical assistance personnel were working as implementers or controllers on behalf of the aid agencies. Very few were women. Over the last decades, the modalities of development cooperation have changed. Typical Finnish-funded projects of the 1980s were infrastructure activities, such as harbour construction or well drilling, or forestry training, plantation projects and dairy, with large Finnish technical teams and a topdown approach.

In the late 1960s-70s stipended volunteer workers went to Tanzania with support from the Finnish Government (kehitysjoukkue) in a variety of community-level roles. In the late 1980s the Finnish Volunteer Service began to send volunteers to developing countries. At the same time there were increasing opportunities to work internationally as researchers or with Finnish Non-Government Organisation projects. However, in 1991 during economic recession in Finland, there were steep cuts in aid funding and opportunities reduced (Koponen, 2005).

In 1996 the OECD DAC promoted a new aid paradigm regarding the quality of aid delivery, with goals of local ownership and partnership. The move over time has been to smaller, innovative projects, with perhaps one or two international staff (not necessarily Finns), employed by consulting companies. Provision of technical assistance has decreased, as capacity in recipient countries has increased. The required skill set has changed from specialist technical skills to a focus on generalists, with project management expertise and a range of 'soft' skills (covering areas such as gender, human rights, environment and capacity building) who work as advisors and capacity builders, rather than implementers in most cases. This can be seen in the changing professional backgrounds and gender of JPOs recruited by Finland. White et al (2011b) found an increasing proportion of social sciences graduates being recruited, and a large increase in the proportion of women. In the 1990s the proportions of Finnish male and female JPOs were roughly equal. During the last decade recruitment of women had risen to 82 per cent. This gender change is gradually reflected in the other categories of the spectrum as JPOs graduate into other roles.

\section{Theoretical understanding}

The relevant literature to my research (and the research questions I base on it) considers the issues of motivations, positioning with respect to others, and the rise of a development culture. 


\section{Motivations}

Several researchers have considered the motivations of those working in development. Fechter (2011) describes the diversity of people working in 'aid', comparing their lives with others working in international fields, such as the military and business. She finds the motivations of those entering development to be mixed, though usually including some altruism. de Jong (2011) also discusses the notions of altruism in NGO work. She considers the commonly held assumption that NGO workers should be free of selfish motivations, as their privileged position as (usually) a western, educated person means they have a responsibility for the welfare of others; yet she finds that this binary interpretation (selfishness or egoism, versus altruism) is too simplistic when considering individual motivations. Smith and Laurie (2011) describe the balance in international volunteering between career imperatives and altruism, producing a complex balance of social justice, enlightenment and cv improvement.

Gift theory has been used to consider the motivations for giving development aid, and, by extension, for working in development. Silk (2004) considers there is rarely pure altruism, including within the aid industry. Shutt (2012) describes how aid is given and accepted as part of a process to establish social relationships, but can also include acts of symbolic power by the donor, invoking various degrees of reciprocity. There are economic inequalities within the development aid complex. The donor wields more power than the recipient. Even if individuals have pure motives and share local conditions, the bottom line is that the foreigners can leave.

Moral motivations are one reason why people may be encouraged to work in development and improve the lives of strangers. However, pure altruism assumes that a gift that is given freely, with no reciprocation, with most researchers considering this is an ideal only. Göbel et al (2013) reviewed the literature regarding reciprocity using an axis, defining reciprocity stemming from calculations of benefit as 'exchange'; and reciprocity stemming from a sense of obligation or duty, as 'giving'.

Eriksson Baaz (2005) finds many contradicting narratives in her interviews with development workers (mainly from NGOs), who vacillate between embracing and rejecting solidarity and altruism. Her respondents often were driven by idealism at first, but they gradually became used to the job and the environment (sometimes stressful and even dangerous), and stayed because they enjoyed it. 


\section{Positioning}

NGO staff and international volunteers interviewed by Eriksson Baaz (2005) conceptualize themselves in relation to the 'other' - their African co-workers and other development cooperation workers. A modest lifestyle was considered a marker of solidarity in their eyes and they demarcated their position clearly, "characterised in the differentiation between "us", who at least have quite modest living conditions and live closer to the local communities, and "them", the development experts whose standard of living is outrageous and who spend their lives at the Sheraton cocktail bar or the yacht club' (2005:82). This was echoed by many of my respondents.

A stereotype, simplified and popularized by Hancock's 'Lords of Poverty' (1989) of selfish aid bureaucrats living the high life at the expense of locals, is counterbalanced in the public eye by images of 'heroic' aid workers. These moral judgements are based on the perceived salaries and conditions of international experts in relation to those they are aiming to 'help', as well as their perceived incompetency. Yet Stirrat (2008) notes that a comparison to the salary levels paid in western countries is rarely drawn. He evokes the stereotypes (often self-applied) of mercenary, missionary and misfit. He considers that 'mercenaries' (or development professionals working for donors or consulting companies) feel guilt at their advantageous position, as well as uncertainty as to their value of their efforts. 'Missionaries' or NGO workers he identifies as having a vocation driven by a sense of duty, though also a stereotype of amateurism and ineffectiveness. He also finds that these two categories are converging; while some workers begin in, or after some years in development work turn into, the third category, that of 'misfits' who do not fit in at home. Fechter (2012) noted the critiques of aid work; in particular, discomfort with the idea that development workers can make a good career from poverty. She describes how many of her respondents compared themselves to other foreigners who they felt were earning more or living an extravagant lifestyle. In some ways this made them feel better about their own comfortable position in comparison to local counterparts.

The expectations of donors, recipient organisations and co-workers tend to push individuals into narrowly defined roles, emphasising either technical skills (on the right hand side of the spectrum) or building relationships (on the left hand side), but not both (McWha 2011). McWha uses social identity theory (and its extension, self-categorisation theory) to explain how job titles, salary and power divide the different categories of aid worker from each other and from local counterparts and beneficiaries, accentuating the tendency to othering. Shutt (2006) described her own move 
from idealistic volunteer to consultant, accompanied by internal conflict over her desire for salary and status.

\section{Development culture}

Prominent among recent 'aidnographers', Mosse $(2005,2011)$ has worked as a consultant in bilateral projects. He discusses the 'messy' realities of development work, where all types of development professionals negotiate their place in complex societies and bureaucracies, while maintaining their moral-ethical motivations. He recognises the mobile and close-knit communities of experts, who make up a cohesive culture. Crewe and Harrison (1998) describe the similarities between colonial attitudes toward local people, and the attitudes of development workers in more modern times. They consider that it can be difficult, even for the best-meaning workers, to avoid the assumption that modern Western culture and its technology ('development') are superior to that of the locals. Desmond (2007) looks at forest fire fighters whose job is perceived to be risky. He applies Bourdieu's ideas on habitus - that we are shaped by the circumstances and culture surrounding us and become accustomed to them. It influences our lifestyle, values, dispositions and expectations. The culture of technical development cooperation influences those on the spectrum, who tend to self-identify with their own group (such as NGO staff or donors), but also with the broader development culture. Rajak and Stirrat (2011) noted that it is rare for people to leave development and work in other careers, although they change contracts regularly. Stirrat (2000, 2008) also considers that NGO workers and development professionals have a shared objective - a modern society, based on free individuals and liberal democracy, irrespective of the culture it is anchored in. He felt that the dominant thread was a belief in modernism and enlightenment as a means to change the world, much like their missionary and colonial precursors. He considers the tools, such as terms of reference, logical frameworks, reports and even participatory rural appraisal, are elements of the cultural performance of those working in development. This concept of a development culture is something that also emerges in my research.

\section{My own movement from 'missionary' to 'mercenary'}

I draw upon my experience of twenty five years in development cooperation. My experience as a volunteer with Australian Volunteers International has inevitably affected my view of technical cooperation. The volunteer program emphasized experiential learning and relationship building, within local organisations and facing resource constraints. Technical assistance was considered important but complementary. I went to Nicaragua in the 1980s with explicit political (solidarity) 
as well as humanitarian aims. I didn't consider my career at the time. In fact, my career as a veterinarian took a step backwards, though the experience led to a new and unexpected professional direction. I travelled to Nicaragua first as a brigadista (an unpaid volunteer, learning and working in solidarity with the Sandinista revolutionary aims) and continued working in solidarity activities in the UK and Australia. I then went back to Nicaragua as a long-term volunteer (or cooperante, receiving a stipend), working as a veterinarian for the government. Perhaps naively, I hoped I could make a contribution to building a just society. After almost three years I returned home and was satisfied that my contribution was useful, although it had its ups and downs. I consider I also learned a lot, both professionally and personally, particularly from my co-workers - something that led me to want to continue to work in development. I understood better the reality of the field and I worked at the level of ordinary Nicaraguans, facing similar constraints, rather than having access to money and equipment. Typical of many development workers, I married into a different culture (in my case a Finnish volunteer, though of course many marry locals), leading to a life-long cultural exchange and relocation to Finland. I then worked for an NGO volunteer-sending agency, volunteered on the committee of an international NGO, and worked for a commercial consulting company that provides technical cooperation to a wide range of donor-funded projects and programmes, including working myself as a short-term consultant. Rather than having the chance to build relationships and work in a participatory fashion, shortterm assignments often mean I work under pressure to deliver reports and recommendations to the donor. I face conflicts between doing what is best for local beneficiaries, for national stakeholders, for the donor and for my reputation.

With my 'accidental' career reflecting the overall professionalisation of the industry, where should I position myself now? Is it ethically acceptable to be making a good salary from poverty reduction? As I have moved between categories (including as a researcher), I have questioned whether there are essential differences between types of development worker or the age of the individual. If differences exist, do they make a difference to the end result?

\section{DATA AND METHOD}

This paper is based on interviews with a range of Finnish volunteers, JPOs, technical advisors, NGOs, consulting company staff, researchers, embassy and Ministry for Foreign Affairs staff. Data on age, gender, professional education and work experience were collected, and the interviews were recorded and transcribed. I also draw from earlier research conducted with Finns who have participated in JPO postings with Finnish bilateral projects or with multilateral 
organisations, utilising written questionnaires (White, 2011, unpublished). This earlier research explored the experiences and motivations of early career development workers, but questions remained as to whether their attitudes would change with more experience. The work with the second batch of respondents allowed me to explore this further, with a group that varied considerably in age and experience. I chose to use interviews as a methodology as it had the potential to go deeper.

Interviews were carried out with twenty eight persons in a range of posts in development cooperation with an average age of 46.2 years (ranging from twenty nine to sixty five years at the time of the interview). The year of their first experience in developing countries varied from 1977 to 2010 , with a median of 1990 and an average of 1992. The subjects were chosen via purposeful sampling in order to ensure a range of backgrounds. I used personal and professional contacts to identify interviewees. Some were known to me at the time of the interview, while others were strangers. The aim was to cover all types of technical cooperation and a range of viewpoints ${ }^{1}$.

I used general questions to guide the interviewee to discuss their life history and reflect on their experiences, and the successes and failures of development. We discussed the respondents' motivations for working in development (particularly in their first post), as well as attitudes towards salary, working styles, other types of technical cooperation and relationships within their team and community. I asked them whether their attitudes and perceptions had changed over the years.

In the questionnaire-based research, I contacted by email all identifiable persons who had worked in Junior Expert posts in bilateral Finnish-funded projects (thirty six in total were identified at the time of the research) as well as some Junior Professional Officer positions with multilateral organisations. The people were identified via an advertisement on a relevant NGO website, and personal contacts, as there is no record kept by the MFA. Some knew me prior to the contact, but more than half were strangers. The main target of the study was the bilateral JPOs, but any multilateral JPOs who expressed interest were also sent a questionnaire. For this paper I refer to all

${ }^{1}$, The posts of interviewees at the time of interview were: Finnish embassies ( 3 respondents), the Ministry for Foreign Affairs of Finland (2), Junior expert in a bilateral project (1) and multilateral JPO (1), consulting company home office staff (7), NGO staff (5) consultant in a long-term project (1) and independent short-term consultant (1), researcher / academic worker (3), volunteer (1) and non-aid related business (3). Of the 28 interviewed in total, 6 were aged less than 34 years at the time of the interview. 10 were men and 18 were women. Three no longer worked in development cooperation at the time of the interview. 
as JPOs. Responses were received from forty six persons working in bilateral or multilateral junior postings (thirty three and twelve respectively), with an average age of 33.3 years at the time of contact. Three bilateral JPOs who were contacted didn't respond. It is thought that the majority of people who had worked as Finnish bilateral JPOs at the time of the research were contacted.

The questionnaires covered the full cycle of the JPO's placement, from prior experience, recruitment and briefing, experiences in the post, and returning home. They were asked to reflect on their initial motivations, how things went in reality, and what barriers they faced in finding work subsequently in development.

The interviews were recorded and later transcribed, and the interviews and written questionnaires were coded (with Atlas.ti and Word/Excel). My approach was content analysis as well as discerning patterns, following the topics that were expressed.

There is some risk of artefacts as a result of the variation between the methods used. The JPO study surveyed all possible members (the 'universe') of the bilateral JPO cohort, while the interviewees were deliberately selected from the larger potential pool of Finns with experience in development. It is possible that the selection process held some bias, and that I selected respondents with similar world views. However, I made a deliberate attempt to interview people who had held different roles, rather than simply those I knew. In the face to face interviews there was a chance to build rapport, and the interviewees were relaxed, often sharing very personal stories. In contrast, the act of writing down a response, in the case of the JPOs, might encourage self-editing, with the potential audience in mind (and lack of interest in writing a long treatise).

\section{INITIAL MOTIVATIONS}

Why did the respondents first decide to work in development cooperation? Based on the diverse literature on gift theory or reciprocity, I endeavoured to explore whether the respondents had a clear expectation of a return for their 'gift' of service, be it in the form of money or professional experience, or whether there was an altruistic focus. My original assumption was that it might be possible to categorise the results according to the role the respondent was holding. Using the terminology of Stirrat, it could be expected that the volunteers and NGO staff at the one end of the spectrum would be the 'missionaries' or altruists, and those working for consulting companies or donors would be the 'mercenaries' or realists. However, during the interviews it became clear that 
most respondents had held many roles across the spectrum and therefore were very difficult to categorise.

The motivations for the first development posting tended to break down into three main categories:

- Those who were keen to travel and see new cultures, and as was often mentioned, 'to do something interesting'

- Those who wanted to 'do good' or improve the lot of people living in developing countries

- Those whose main focus was professional.

There was a lot of overlap, with many people mentioning more than one motive. The responses of those interviewed can be summarized with the following hierarchy of motivations.

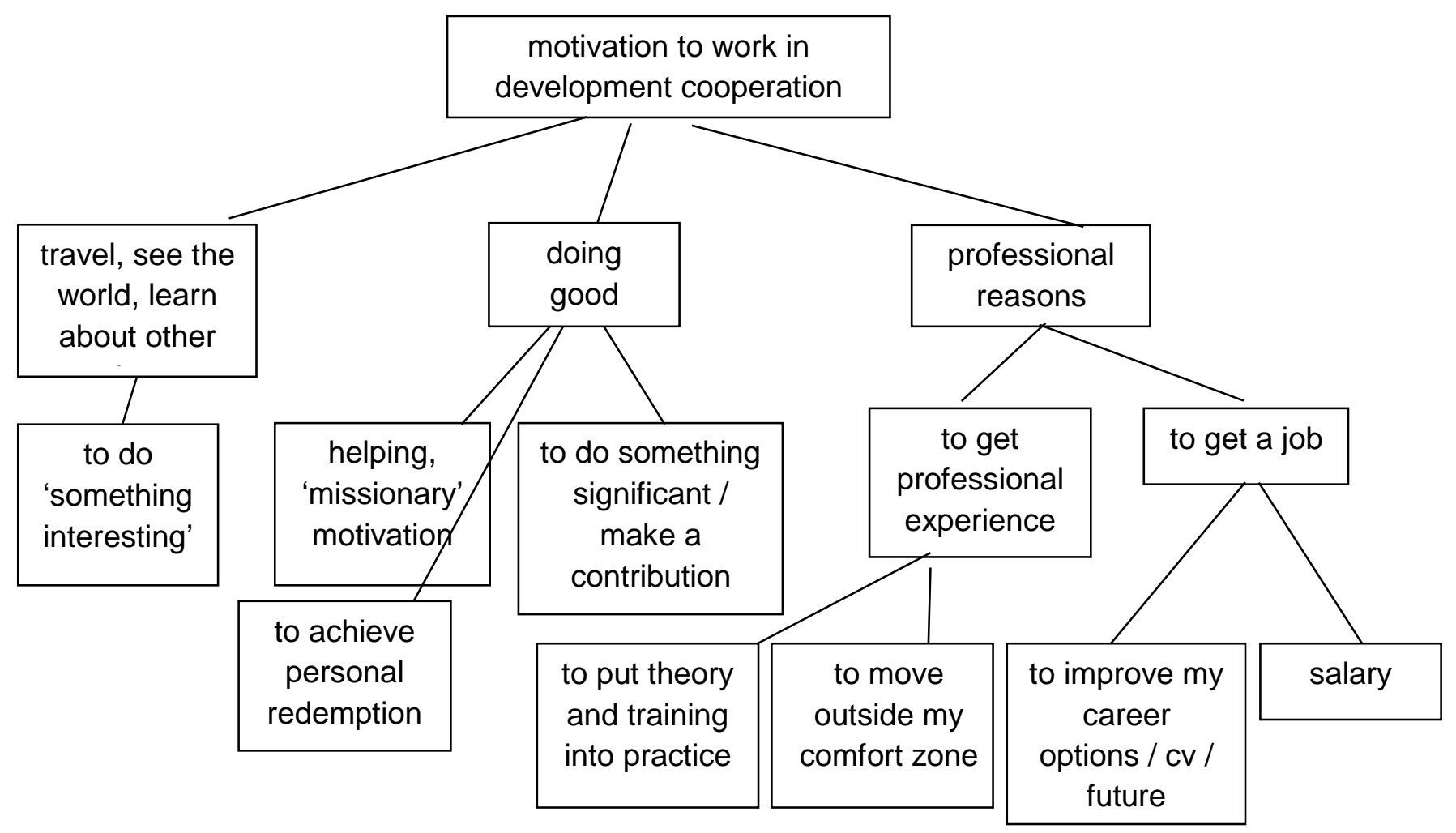

Figure 2: Hierarchy of motivations

Of the 15 respondents who first began work in development during or before 1990, 13 mentioned the attraction of travel and learning more about the world (and it was the most frequent response from all). Finland had no colonial past, and was a more closed country in those days, with international travel commonly consisting of InterRail or backpacking holidays within Europe. Most respondents came from a small village or farm and were keen to get away and out to a 
different world - for some, even more recently, that was a very strong push factor. Working in development gave a glimpse into more distant cultures. This often (11 of 15) was combined with a wish to 'do good' or 'help' and improve the social welfare of others. It was sometimes influenced by political and solidarity movements of the time. Several mentioned feminist campaigns, Africa, the Vietnam War and political activism as providing the spark of global responsibility. For instance, an NGO staffer at time of interview said:

I had this ideology of global social welfare and sharing resources more equally. I had done my studies, I had some sort of skills, and I thought, why don't I work for those less privileged, instead of working in Finland? I think that was very common then, at that time, not necessarily nowadays - this social ideology of sharing - some kind of awakening of my global responsibility. (I-15)

Among the responses coded as 'doing good' were those whose interest started with missionary stories during childhood, as well as those who used a different term - 'to do something significant' (though some might argue that this is more linked to self-interest or egoism, than to altruism). A consulting company staffer at the time of interview noted:

I wanted to see things from a wider perspective. I think it was more curiosity when I was studying, though there was this ideological motivation, to help...Also the chance to use the skills and knowledge I have to do something significant, in a way. (I-4)

In one case a respondent mentioned that links to the church had influenced him, both in the sense of doing good and opening his eyes to the exotic world beyond. However, none of the interviewees had worked as missionaries, nor expressed evangelical motives.

I divided the category of 'professional reasons' further into professional and personal development; and just getting a job. Professional reasons were significant for those who first went into development work during the recession of the early 1990s, as well as now. In her research on the motivations of people working in development in the 1990s, Leinikki (1998) noted that most common was the desire to help developing countries. However, she also reported that severe unemployment in Finland at the time caused a significant push. One of my respondents commented:

It was 1992...93. It was very difficult in Finland then and it was a good option to go somewhere else...the timing was perfect, because it avoided all the trouble in Finland then. (I10 - Consulting company staffer at time of interview) 
Another motivation was the desire for change and adventure. Some mentioned a professional interest in testing themselves with real issues, and that in Finland development had already progressed a long way. Respondents mentioned the importance of trying out the skills and knowledge they had learned at university (testing what they were capable of), and stretching their technical and intellectual capacities (10 of the 15 leaving earlier, compared with only 3 of 13 leaving after 1990). Several had been encouraged to apply for development work during their studies by hearing stories from pioneering Finnish development workers in engineering and forestry, who had become Professors. Many used the word 'opportunity', focusing on the experience rather than considering this a long-term career. An NGO staffer commented:

When I first went away I was a researcher...I was becoming a professional and needed field experience... to see how it really was. I didn't really think about being in the development 'business'. (I-3)

Two respondents mentioned a degree of being driven by personal experiences, which I have labelled as 'seeking redemption'. To some extent, they were saving themselves. Working in gender issues allowed one to deal with her personal demons:

One day we were preparing a presentation for Beijing ... as we were doing this one woman asked "I was wondering what motivates us. How many of you have experienced sexual abuse?" And you know what? Almost everyone raised their hands. So it was not just 'doing good' - but in a way you are responding to your own wounds. There are two ways of responding - you can either become another person who wounds others, or you become someone who fights against this. I was among those who lifted their hands up. (I-17 independent consultant at time of interview)

The majority of the respondents (all but one) expressed motivations that combined some desire for professional fulfilment and learning with a wish to 'do good', no matter where they were in their career. Their attitudes towards issues such as capacity building, styles of working and relationships within their team and community, were varied. However, those respondents that had held many roles of different categories, as well as those who had more years of experience, appear to have a more balanced view of the different types of technical cooperation. Despite becoming more pragmatic with age and experience, they still mostly expressed the wish to 'do good'.

The motivation is and has been the same - a desire to do something concrete to help people who need help; my 'idealism' has maybe changed from the early years and as this has become 
my every day work, but the idealistic aspect has remained. (I-2 - consulting company staff at time of interview)

In contrast to the interviewees described earlier, none of the respondents to the written questionnaire (who were in general, younger and early in their careers) mentioned travel and seeing the world, although it could be understood that 'interesting experience' (second most common response -45 per cent of respondents) and 'working in a developing country' (third most common, 30 per cent) are probably the evolution of that motivation nowadays. There are many other channels for travel in 'exotic' countries now, and Finland is now more open than in the 1970s and 1980s.

I expected hard times, but I also expected getting a huge amount of experience, maybe a rewarding feeling of imagining that we were "doing good", and a lot of unforgettable memories. (B-11 - bilateral JPO)

The most commonly expressed motivation was gaining relevant professional experience (68 per cent) that might facilitate a career in the development industry, with the United Nations or other organisations. This is hardly surprising, as one of the stated aims of the Ministry for Foreign Affairs when financing JPO posts is to ensure representation of Finns in the multilateral agencies:

Being a JPO opens a door for a young expert to gain invaluable working experience in an international organisation, which is very useful for later career development. (M2 multilateral JPO)

I left to X country with the sole purpose to gain work experience and to start my career in international development. (B-9 - bilateral JPO)

Notably, few of the younger JPO questionnaire respondents mentioned idealism or 'doing good' (although it was a common response of the volunteers interviewed). Only two bilateral and two multilateral JPOs (from 46 questionnaires returned) mentioned idealism or altruism as a motivation in their decision to work in development. 'I wanted to do something meaningful; I expected that I could make a difference' (B-33 - bilateral JPO). To some extent this could be an artefact (affected by written rather than verbal responses), and self-editing by the respondents. They may have felt pressured to mention what is considered appropriate. It is not seemingly politically correct in the twenty first century to aim to 'save the world'. 
The discourse of development has focused on a critique of aid (often with good reason). Recent entrants to development work are probably less naïve than those of the 1980s. A younger interviewee noted that even though he held some ideals of 'changing the world', his academic training and 'that generally cynical appearance one must give' prevented him from voicing this motivation publically (I-18). Cynicism is the opposite extreme from the naivety of some starting out in development. There are several blogs on aid workers active at present, with the posts tending toward the very cynical ${ }^{2}$. Yet, ever increasing numbers of young professionals are interested to work in development, and prepared to do temporary and low paid jobs in order to achieve that aim, while others in their cohort choose steady, salaried posts at home. Where earlier development workers in the 1970s and ' 80 s rarely had development training, but instead a focus on technical skills, currently there is a blossoming of development studies courses worldwide.

Increasing unemployment has meant that graduates need to make choices for the sake of their career. Some young development workers take on constant internships and volunteer postings in the absence of 'real work', endlessly improving their cv in hope of scoring a job. While the older respondents in this study tended to have 'fallen into' this career, taking the first post as an exciting opportunity or side-track, younger respondents made a deliberate career choice. Eyben (2012) and others note that the professionalism of international development work has accelerated since the late 1990s, making it more difficult to enter the development field. Just as the role of a development worker has become an acknowledged career, the opportunities to take that path are diminishing. de Jong (2011) noted that the careerism of international NGO staff has been an emerging trend. NGOs that have traditionally focused on altruistic aims now have donor-imposed requirements for results-based management and measurable outputs. There is increasing blurring of the distinctions between the work of NGO staff and consultants, and even, at times, the remuneration.

\section{SALARY AS A MOTIVATOR - MAKING MONEY FROM DOING GOOD}

Few interview respondents considered salary was an important motivator (three altogether and only two during their first post). This was particularly emphasized by those who began to work in development during recession in Finland (both in the early 1990s and today). Six respondents expressed guilt at the relatively high salaries they earned in comparison with local staff. Others hadn't considered salary initially, but it had become increasingly important:

\footnotetext{
${ }^{2}$ for instance, http://stuffexpataidworkerslike.com/
} 
I felt that I was new and starting out and learning, having a good salary there was just a bonus... [but in a later post] I was getting into serious stuff, where there was money involved and I was responsible for things. Salary was a motivation by then. (I-21 - consulting company staff at time of interview),

The remainder responded that salary was not a critical factor, although for some it was important to be on a level appropriate to their position, or to be able to cover their needs:

If you had a very low salary it would have an effect. But gaining a certain level, giving you the security that you are able to live properly, raise your family, pay the bills, that's always been enough for me. (I-4 - consulting company staff at time of interview)

By then I had a family. I was the only breadwinner. So in that sense it was important. But while it was a good salary for one person, for the whole family it wasn't bringing more than it would have been if we were two breadwinners in Finland. (I-12 - NGO staff at time of interview)

For the self-funded volunteers, paying their own way, salary at the time wasn't a motivation, though usually they appreciated the benefits this short period would have for future possible jobs, apart from improving their development understanding.

In contrast to the responses of those who were interviewed (who were on average older), 20 per cent of JPOs expressed the view in the written questionnaire that salary and job security were important, as their earlier experiences as volunteers or interns gave little financial backing.

No-one working in development can do so forever as a volunteer, unless they are independently wealthy. At some point, everyone needs a salary, whether as an organisational staffer, a researcher receiving a grant, or a consultant.

Watts (2002) noted that low pay was the element that many of his stipended volunteer respondents in Cambodia used to self-identify, distancing themselves from expats, although recognising that they were paid much more that local counterparts. However they did not claim to be altruistic, recognising that they would gain something from the experience. Shutt (2006) also noted that pay disparities with other expatriates may impact negatively on the motivation and perceptions of volunteers. 
The Finnish respondents may be constructing the narrative to some extent, and be reluctant to 'admit to' being driven by salary expectations. Yet most of the interviewed respondents in this study had not considered salary to be a significant motivating factor, beyond covering their basic needs. Instead, most respondents stated that they were motivated by the work itself, and other nontangible benefits. This coincides well with Stirrat's findings (2008) that both the 'missionary' and 'mercenary' share feelings of guilt and altruism. In addition, he sees a convergence in the objectives of the work and methods used by development consultants and NGO staff, as well as increasing professional demands on both.

\section{EXPERIENCES OF THE FIELD AND AFTERWARDS}

Having looked at the motivations for development work prior to departure, it was valuable to explore the experiences in the field, and see whether there were differences based on the role. I found that while many respondents, despite their role, share similar motivations and ideals, the expectations of their role force them into different ways of working. Several mentioned the constraints of their terms of reference, the expectations of the donor and local counterparts, and frustration at their treatment by local people. This could be interpreted as reflecting the gap between the status they had expected, as an international advisor with relatively good salary, and the reality in the field.

It is possible to see considerable variation of outcomes, depending on the individuals and the jobs. Some roles (particularly as experts or donor staff) simply do not permit foreigners (in this case Finns) to work at the pace of their counterparts. Instead, they are forced into a fast-moving leadership role. Yet others, particularly those posts at grassroots rather than national level, allowed development workers with a commitment to real participation to build relationships and make significant positive contributions.

Despite the JPOs' expressed focus on professional motivations, the responses indicated that the most positive outcomes of their posting were usually those that involved contact with the community, building relationships and developing personally:

The real highlight was to notice, that 'I can make it'. That I can live there alone, and that I can manage the project and all its responsibilities, that I'll survive. Also the feeling that I was useful, needed, and that the locals really appreciated my work and me as a person, was really 
worth all the loneliness, homesickness and feelings of being misplaced in a hostile environment. (B-11 - bilateral JPO)

Thinking back, it is the fact that I learned a lot during my assignment - not the kind of technical things that you can directly put in your cv, but a deeper understanding of the realities in a very troubled developing country and thus of the challenges and limitations of development cooperation. (B-19 - bilateral JPO)

Although the majority did eventually continue to work in the development field, some JPOs also expressed frustration at their inability to transition immediately into further assignments as longerterm 'experts' due to insufficient experience. The complaints could be summarized as a feeling of disappointment and frustration that their expectations were not met.

As noted earlier, there has recently been a trend towards feminisation of the technical development cooperation field, in Finland and elsewhere. Interestingly, almost all female respondents reported that they did not feel they had experienced gender discrimination in the field. Instead, they were in a very privileged position and were often treated as men.

'Being a woman - I don't think it made a difference... You are white so they treat you

differently - you are a donor, walking dollars, an honorary man.' (I-20 - donor staff at time of interview)

Youth was considered a more significant divider than gender, particularly for the young, less experienced JPOs. In contrast, the choices made by the respondents themselves are often gendered. The majority of women choose to return to or base themselves in Finland for family reasons (at least in the mid-career stage), rather than accepting peripatetic careers (White et al, 2011b).

\section{CHANGING MOTIVATIONS AND PERCEPTIONS, POSITIONING AND HABITUS}

As development workers advance in their careers, they tend to move from volunteer or research roles into donor agency posts, consulting roles or positions in consulting company home offices, reflecting the left to right movement on Figure 1. It is less common to move out of development work altogether, except when the worker could not find further posts. For most, no matter how altruistic their early motivations might have been, the work gradually becomes a job. In contrast to younger respondents, many of the older interviewees felt that they had not planned a career in 
development but simply ended up there. In subsequent assignments, the extremes of lifestyle are less shocking, the work is familiar, the risks less jarring. It becomes 'what I do'. A consulting company staffer commented:

It was probably a coincidence. At one point I took one path without thinking about it. And then I continued that path. I never did conscious career planning one way or the other. (I-21)

Had the opinions of interview respondents changed significantly over the years? Despite the different positions held, there was surprising unanimity of responses. One might have expected that the initial idealism and altruism might have worn off after the worker had been exposed to more development assignments, the possibilities of failed projects, problematic relationships and corruption. Instead of becoming cynical, they had grown pragmatic and in many cases they maintained their ideals.

When I've gone away later, my motivation is that I'm a permanent worker in the company and it's part of my job. But of course you have to believe that it is somehow significant, otherwise you wouldn't really be able to do this work. (I-4 - consulting company staff at time of interview)

One respondent noted her changing opinions, stating that she had seen good and bad examples of technical cooperation, and was undecided.

I have gone from someone who was very critical, to someone who was OK with it, and now I'm coming back to being critical again. (I-9 - researcher at time of interview)

Only two respondents (both consulting company staff) were significantly negative about development work, while continuing to work in it:

Gradually my opinion on development cooperation has changed. It became more pessimistic than realistic. I don't think there is anything that works. Anything we have tried boils down to the same thing, very burdensome, very difficult. (I-21)

What were the interviewed respondents' attitudes towards other roles in the spectrum of cooperation, both when they first started and now? Most had started as researchers, volunteers or JPOs, and reported a somewhat negative attitude towards consultants or multilateral staff early in their career.

I was really horrified about the expat Finns there. I thought it was awful that they don't try to engage with the locals, they don't speak the language and they drive big 4WD cars and live in 
a compound. (I-12 - NGO staffer at the time of the interview, talking about her first experience as a volunteer)

I had a big culture shock... we spent time with friends working with the UN and yes, their lifestyle really shocked me. I thought, how can this be, what do you know? But you can't be a volunteer forever. (I-13 - an ex-volunteer, now no longer in the aid business)

As they had got older and held a range of consulting posts, their opinions had mellowed and they became less critical:

At that time I was very critical. We were living in local conditions and a neighbourhood with no other white people, taking public transport, being as local as possible, and you identify with the group you are in. But to be honest, the [consultants] I met were motivated, inspiring, dedicated. They were good people and were trying to do something make the world a better place. They weren't just there for selfish interests. (I-11 - NGO staff at time of interview, commenting on her volunteer posting)

One respondent stood out as having a quite different attitude and language to the others: Somehow it is easier [to be a short term consultant]. You do some small work and hand over the results. You aren't responsible for using the results. It's like having a nice trip of a few weeks and that's it....the cases where I have been short term, I have been the top professional. I know everything and the others know nothing. So everything you say is correct and is according to some standard. I know everything, I give the training, they are interested to listen. (I-10 - consulting company staff at time of interview)

This is probably closer to the stereotype portrayed by some researchers (see Crewe and Harrison's discussion of colonial attitudes and power differentials). It is possible that more people feel like this, but apply the veneer of political correctness.

As noted earlier, McWha found that the expectations of donors, recipient organisations and coworkers tend to push individuals into narrowly defined roles (McWha 2011). My interviews demonstrate that while this may be true for a discrete posting, the borders between types of development worker become blurred over time (especially as Finnish development workers are few and there is a lot of movement between roles). While many respondents begin their career self-identifying very clearly with their own 'group' (eg. volunteer, researcher, etc.), and denigrating other categories, they come to realize that the divisions and behaviours are more 
linked to individuals as they continue in 'the business'. This reflects the finding of Stirrat (2008) that there are more similarities than differences between 'missionaries' (NGO workers) and 'mercenaries' (development professionals). There is also a tendency to self-censorship due to the wish to continue working in development and not to alienate potential donors or co-workers (noted also by Mosse, 2011).

As they learn and experience more of the impossible challenges of development on a global scale, development workers are faced with the choice of giving up or focusing on the immediate task. While it is clear that technical solutions will not resolve global inequality, sharing formative experiences with locals and working for small steps (such as providing clean water sources, or improving production and consumption of nutritious food, building local capacities to deal with environmental hazards) gives development workers a chance to make change.

I think I'm stuck since having my 'enlightenment'! It is still the ideology that drives me. I still get these whims of getting really angry about inequality, discrimination and so on. I'd rather still try to do something, even if it's not the best option, than to stay home and complain. (I28 - volunteer at time of interview)

Many interviewees noted an element of unease about their privileged circumstances vis a vis local counterparts. Why do development workers feel this unease? Presumably it is the constant reminder of poverty and inequality, something easily forgotten in developed countries. Development workers are expected by some to be motivated by altruism, which makes earning money problematic, especially when many projects have poverty reduction as their objective. The ideology of altruism sets development workers apart from other western professionals working outside their country (eg. in military, diplomatic or business fields). As noted earlier, according to Fechter (2012:1481) aid workers sometimes consider that "'living well" while "doing good" implies that the acts of altruism are less pure — tainted by the material benefits one gains — and therefore accumulate less spiritual or moral value for the aid giver. While some live a more comfortable lifestyle than they would at home, many are making sacrifices to work in development. Heat, exposure to disease and the risk of violence, boredom, cultural exclusion, uncertainty, distance from family and friends are some of the negatives; which are balanced against the undoubted positives of exotic travel, stimulating work, power, salary (in some cases) and the sense of moral reward. On balance, it appears that for most, the positives win out, and they try to stay in development work. 


\section{STAYING IN THE DEVELOPMENT CULTURE}

An interesting element of technical development cooperation is that once people have begun to work in 'the business' they rarely leave voluntarily (or at least in so infrequently that I wasn't able to identify them). My cohort includes only Finns, but the observation is anecdotally true in at least other Nordic countries. As mentioned earlier, Rajak and Stirrat (2011) noted this was encountered in the aid industry in general. They consider this to be a combination of an 'addiction' to the lifestyle, as well as perhaps a deskilling with regard to non-aid jobs (becoming a 'misfit'). Lienikki (1998) noted the circulation of the same people in the Finnish aid business. She considered that one reason might be that their experiences from developing countries are not appreciated by Finnish employers and they find it difficult to find work again at home. Some respondents commented on the same problem. Although one reason cited for Finland to support development cooperation is to increase the internationalisation of Finland, it may take time for the local employers to appreciate this.

There was no clear correlation between the age of the respondent at the time of the interview, and the job held, nor the number of different types of role held. In Figure 3 below the average number of different roles held earlier by those interviewed for this study are illustrated. All had held more than one role - even the volunteer, who was at the start of her career. The volunteer and NGO staffers had experienced fewer types of role on average (three types of post). 


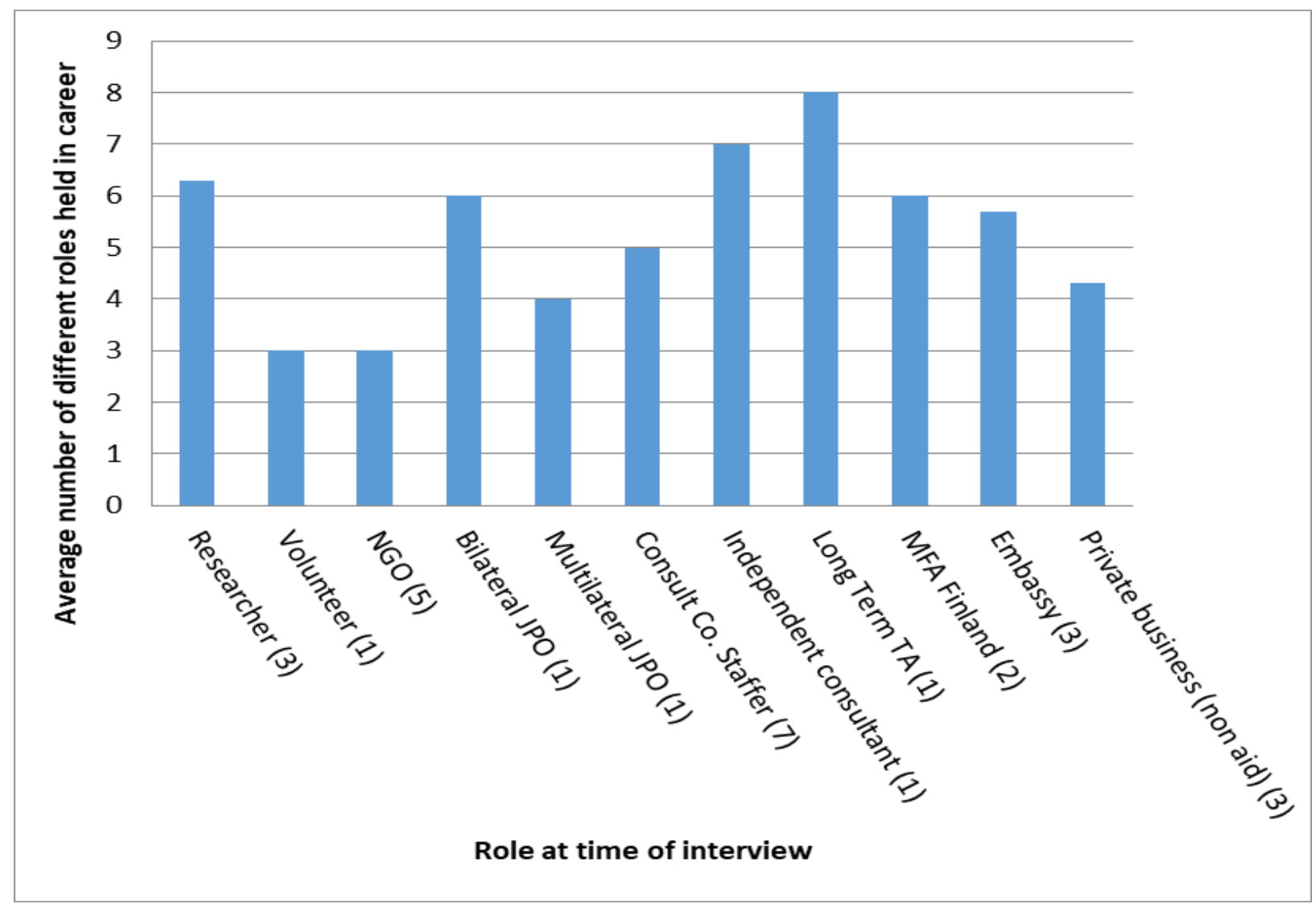

Figure 3: Average number of different roles held by respondents earlier in relation to their role at the time of the interview

Among the thirty three bilateral JPOs who responded to the questionnaire, all but four have gone on to one or more other roles in development cooperation.

In earlier research on Finnish multilateral JPOs (White et al, 2011b), 138 persons out of a total of 165 respondents, said they had continued to work in development / international cooperation after their initial assignment. Of those who didn't, only four persons said they were not interested in working in international development cooperation any more.

Most respondents of the present study struggled to think of development workers who had voluntarily walked away from the business. Two of the interview respondents had done that (they were specifically approached as deviant cases). In both cases they cited burn-out with the lifestyle of frequent travel and inability to plan their lives at home. Yet even they were nostalgic and did not rule out a future role: 
There is no real exit strategy for people in the development business. It's not easy to leave all that behind. Maybe because working in development cooperation is like a drug - once you've tasted it you are hooked. (I-24 - private /non-aid business at time of interview)

Given the risks, uncertainty and ethical dilemmas, what is it that 'hooks' people? The concept of habitus is evident. Work in the field of international development moulds participants socially and organisationally, giving a shared vocabulary and ethical viewpoint (though of course this lack of diversity could be problematic - the habitus may influence them unduly, giving a limited world view and constraining them from perceiving other possibilities). Working in a project in a developing country, away from friends and family, tends to lead to overlapping of social and work life. Many note the close bonds they have formed with co-workers, and the difficulty of explaining the work to outsiders beyond clichés. The financial benefits for some make it worthwhile, but for most this is a background issue rather the main driver to choose this work over another. Undoubtedly there are stresses and dangers, but the good seems to outweigh the bad for most.

\section{CONCLUSION}

I studied the motivations of workers in technical development cooperation. For those first starting out in the 1970s, '80s or '90s, travel and adventure, 'doing good' or political motivations were most important. Their current post did not significantly change their motivation or attitudes. However expectations and requirements of their role force them into different ways of working. While some spoke in the interviews of feeling an obligation to pay back something to those less fortunate than themselves, all had other motivations also. All described what they have gained through their experience. They mention personal relationships, skills (language, understanding of another culture, development project management skills), salary and career. It is likely that most people go into development work with some expectation of receiving as well as giving.

For those answering the written questionnaire in their late twenties or early thirties (those who began in cooperation in the 2000s), it appears that professional development and career have become more important, reflecting changes in society and the job market in general. The increasing professionalisation of the development business is increasing the demands on all actors and leading to a more career-oriented attitude towards development work. In agreement with other researchers, I found that many development workers position themselves in contrast to others, 
perhaps as a reflection of their own unease with living well while 'doing good'. Most tended to change their views of others as they aged and gained more experience.

This research demonstrates the fluid movement between categories on the technical spectrum, and the tendency for the different roles to become similar (with 'missionaries' and 'mercenaries' converging), especially with increased pressure from donors for professionalisation.

The study identified a development culture or habitus. Regardless of their doubts about development, it is unusual that people leave to pursue other careers, unless they cannot find assignments. Work becomes 'what they do', for a range of push and pull factors. The majority of people who start in development, continue in this field, but by necessity as well as preference, tend to work in different categories. There are very few who fill only one category of job. Notably, a shared language was used by almost all respondents. It is rare to find a respondent who doesn't share the moral framework of development theory and ethical language, whether they are NGO staffers or well paid consultants. This phenomenon may be seen elsewhere, but it is perhaps more common in Finland due to the fewer Finns circulating in the development sector.

Many respondents could recognize the benefits of a sense of 'doing good' - that an overall purpose could sustain them through boring or questionable tasks. A moral high ground is in-built to the whole system of development, from researchers and NGOs to consultants and donor staff. Perhaps this is why most share an ethical language and reasoning, regardless of their position. The rare persons who do not use politically correct language stand out by comparison. Working in development cooperation has a certain cachet. In common with many in the field, I can recognize the admiration received from outsiders - either for the excitement of the travelling and lifestyle or for the presumed honourable work.

This paper indicates that further research is needed on the evolution of international development cooperation as a profession and as a culture. Most critically, does a different motivation have any impact on the results of development work?

In addition, having observed a difference in motivations and expectations between early and midlate career workers, further research will investigate those starting out. Development studies students at university form part of the future development worker cohort. Do their motivations change during the course and after exposure to development work in the field, and is any 
particular background, motivation or perception at the start, more likely to lead to a career in development work?

\section{References}

Crewe, Emma and Harrison, Elizabeth (1998) Whose Development? An Ethnography of Aid. London: Zed Books.

Brett, E.A. (2003) 'Participation and accountability in development management', The Journal of Development Studies, Vol. 40, No. 2, pp. 1-29

de Jong, Sara (2011) 'False Binaries: Altruism and Selfishness in NGO Work', in Fechter, AnneMeike and Hindman, Heather (eds) Inside the Everyday Lives of Development Workers: The challenges and futures of Aidland, pp. 21-40. Sterling, VA: Kumarian Press.

Desmond, Matthew (2007) On the Fireline: Living and Dying with Wildland Firefighters (Fieldwork Encounters and Discoveries). Chicago and London: University of Chicago Press Books.

Devereux, Peter (2010) 'International Volunteers: Cheap help or transformational solidarity toward sustainable development'. PhD Thesis, Murdoch University, Perth. http://researchrepository.murdoch.edu.au/3551/ (accessed 14 March 2013).

Eriksson Baaz, Maria (2005) The Paternalism of Partnership. A Post-Colonial Reading of Identity in Development Aid, London: Zed Books.

Eyben, Rosalind (2008) 'Power, Mutual Accountability and Responsibility in the Practice of International Aid: A Relational Approach'. IDS Working Paper 305. Brighton: Institute of Development Studies.

Eyben, Rosalind (2012) 'Fellow Travellers in Development', Third World Quarterly, Vol. 33, No. 8, pp. 1405-21. 
Fechter, Anne-Meike (2011) 'Anybody at Home? The Inhabitants of Aidland', in Fechter, AnneMeike and Hindman, Heather (eds) Inside the Everyday Lives of Development Workers: The challenges and futures of Aidland, pp. 131-149. Sterling, VA: Kumarian Press.

Fechter, Anne-Meike (2012) '‘Living Well' while 'Doing Good'? (Missing) debates on altruism and professionalism in aid work'. Third World Quarterly, Vol. 33, No. 8, pp. 1475-91.

Forss, K., J. Carlsen, E. Fröyland, T. Sitari and K. Vilby (1988) Evaluation of the Effectiveness of Technical Assistance Personnel financed by the Nordic Countries. A study commissioned by the Danish International Development Authority, DANIDA, the Finnish International Development Agency, FINNIDA, the Royal Norwegian Ministry of Development Cooperation, MCD/NORAD, and the Swedish International Development Authority, SIDA.

Göbel, Markus, Vogel, Rick and Weber, Christiana (2013) Management Research on Reciprocity: A Review of the Literature. BuR - Business Research, Official Open Access Journal of VHB German Academic Association for Business Research (VHB), Volume 6, Issue 1, May 2013, pp. $34-53$

Hancock, Graham (1989) Lords of Poverty: The Power, Prestige and Corruption of the International Aid Business. London: Atlantic Monthly Press.

Koponen, Juhani (1999) 'Developmentalism vs. instrumentalism: an interpretation of the history of Finnish development aid'. Finnish Aid in Development Working Paper 1/99. University of Helsinki

Koponen, Juhani (2005) Oma suи ja pussin suu. Suomen kehitysyhteistyön suppea historia. Unpublished manuscript.

Leinikki, Sikke (1998) 'Finns in Development Aid: An Overview'. Research Project of Finnish Aid in Development Working Paper 1/98, Institute of Development Studies, University of Helsinki.

McWha, Ishbel (2011) 'The roles of, and relationships between, expatriates, volunteers, and local development workers.' Development in Practice, Vol. 21, No. 1, pp. 29-40. 
Mosse, David (2005) Cultivating Development: An Ethnography of Aid Policy and Practice. London: Pluto Press.

Mosse, David (2011) 'Introduction: The Anthropology of Expertise and Professionals in International Development' in David Mosse (ed.) Adventures in Aidland: The Anthropology of Professionals in International Development, pp. 1-31. Oxford, New York: Berghahn Books.

OECD/DAC (2010) 'Development Co-Operation Directorate Statistical Reporting Directive 40', Development Assistance Committee, DCD/DAC(2010)40/REV1, pp. 15-17.

Rajak, Dinah and Stirrat, Jock (2011) 'Parochial Cosmopolitanism and the Power of Nostalgia' in David Mosse (ed.) Adventures in Aidland: The Anthropology of Professionals in International Development, pp. 161-176. Oxford, New York: Berghahn Books

Shutt, Cathy (2006) 'Power in Aid Relationships: A Personal View'. Institute of Development Studies Bulletin, Vol. 37, No. 6, pp. 79-87.

Shutt, Cathy (2012) 'A Moral Economy? Social interpretations of money in Aidland', Third World Quarterly, Vol. 33, No. 8, pp.1527-43

Silk, John (2004) 'Caring at a distance: Gift Theory, aid chains and social movements'. Social and Cultural Geography, Vol. 5, No. 2, pp. 229-51

Smith, Matt Baillie \& Laurie, Nina (2011) 'International volunteering and development: global citizenship and neoliberal professionalisation today'. Transactions of the Institute of British Geographers, Vol. 36, No. 4, pp. 545-59.

Stirrat, R. L. (2000) 'Cultures of Consultancy’, Critique of Anthropology. Vol. 20, No. 1, pp. 3146

Stirrat, R. L. (2008) 'Mercenaries, missionaries and misfits: representations of development personnel', Critique of Anthropology, Vol. 28, No. 4, pp. 406-25. 
Vaux, Tony (2001) The Selfish Altruist: Relief Work in Famine and War. Abingdon: Earthscan.

Watts, Michael (2002) 'Should they be committed? Motivating volunteers in Phnom Penh, Cambodia'. Development in Practice, Vol. 12, No. 1, pp. 59-70.

White, Pamela (2011) 'Junior Professionals in Finnish Development Cooperation'. Paper presented at the 2011 Conference 'Reframing Sustainability? Climate Change and North-South Dynamics', Helsinki University (10-11 November).

White, Pamela, Seppänen, Maaria and Ahonen, Päivi (2011b) Evaluation of the Junior Professional Officer Programme of Finland. Evaluation report 2011:5. Ministry for Foreign Affairs of Finland, Jyväskylä: Kopijyvä Oy. 